\title{
ANÁLISE DA SOLUBILIDADE DA UREIA COM A VARIAÇÃO DA TEMPERATURA EM SOLUÇÕES ISOPROPANOL+ÁGUA
}

\author{
J. B. RODRIGUES ${ }^{1}$, L. G. FONSECA ${ }^{1}$ e R. A. MALAGONI ${ }^{1}$ \\ ${ }^{1}$ Universidade Federal de Uberlândia, Faculdade de Engenharia Química \\ E-mail para contato: malagoni@,feq.ufu.br
}

\begin{abstract}
RESUMO - A ureia é um composto orgânico com muito destaque na área de fertilizantes e que possui alta solubilidade em água. Neste trabalho estudou-se a solubilidade da ureia em soluções de isopropanol+água contendo 10 e $40 \%$ de isopropanol $\mathrm{m} / \mathrm{m}$ em uma faixa de temperatura que variou de 278 a $333 \mathrm{~K}$. Os experimentos consistiram em colocar a solução de isopropanol+água em uma célula de vidro borossilicato encamisada, juntamente com ureia em excesso. Os tempos de agitação e repouso foram de $2 \mathrm{~h}$ cada. Com os dados obtidos em cada amostragem por gravimetria, determinou-se o valor de solubilidade na temperatura investigada. Os resultados apresentaram baixos desvios padrão o que comprovou a eficiência do método e dos equipamentos utilizados no trabalho.
\end{abstract}

\section{INTRODUÇÃO}

A ureia é um composto orgânico muito presente em seres vivos e a determinação de sua concentração em amostras de sangue é essencial para diagnósticos médicos, principalmente para obter informações sobre doenças renais (Kuralay et al., 2005). Pesquisas também mostram que vários gases de hidrocarbonetos são mais solúveis em soluções de ureia+água do que em água pura (Soper et al., 2003).

Dados de solubilidade de compostos orgânicos podem ser obtidos tanto por meio de medições quanto pela realização de cálculos, porém a predição de dados de solubilidade é restringida pela disponibilidade de dados termodinâmicos de compostos puros e pelos valores de coeficientes de atividade (Sapoundjiev et al., 2005). A solubilidade da ureia em misturas hidroalcoólicas não foi estudada em amplas faixas experimentais de temperatura e concentração do álcool e os dados disponíveis na literatura são bastante dispersos. O estudo de sistemas ureia-álcool é importante para o projeto de equipamentos industriais de separação, cristalização e de extratores. Yin et al. (2006) utilizou sistemas ureia-álcool para preparar fotocatalisadores de titânio mais eficientes na decomposição de substâncias poluentes como o monóxido de nitrogênio. Os pesquisadores Lee e Lahti (1972) analisaram a solubilidade da ureia em água, metanol, etanol, isopropanol e em diversas soluções hidroalcoólicas. Para a mistura de isopropanol+água, foram estudadas as concentrações de 33,3\% e 66,7\% de isopropanol em volume em temperaturas de 0 a $60{ }^{\circ} \mathrm{C}$.

De acordo com Silva et al. (2015) a solubilidade da ureia é diretamente proporcional a constante dielétrica dos solventes. A constante dielétrica é uma propriedade intrínseca e está 
relacionada com a resposta dos materiais aos campos elétricos. A água possui uma constante dielétrica alta $(78,54)$, enquanto que a do isopropanol é de 18,30 (Storm et al., 1970).

O objetivo deste trabalho consistiu em determinar a solubilidade da ureia em soluções de isopropanol+água para as percentagens de 10 e 40\% em massa de isopropanol em uma faixa de temperatura de 278 a $333 \mathrm{~K}$. O interesse nestas concentrações se deve ao fato de não existirem dados sobre a mesma na literatura. O método escolhido para analisar as amostras coletadas foi o método analítico gravimétrico que se mostrou bastante eficaz e consistente para a determinação da solubilidade da ureia.

\section{MATERIAL E MÉTODOS}

\subsection{Reagentes e Unidade Experimental}

Os reagentes utilizados nos experimentos apresentados neste trabalho foram ureia (Fabricante Sigma) com pureza de 99,9\%, isopropanol (Vetec) com pureza de 99,5\% e água deionizada e bi-destilada.

A Figura 1 apresenta a unidade experimental em que foram realizados os ensaios de solubilidade. Os experimentos foram feitos com o uso de duas células de equilíbrio encamisadas de vidro borossilicato, com volume interno de $50 \mathrm{~mL}$, que foram conectadas em série e um banho termostatizado (Tecnal, TE-184) foi responsável por manter o sistema na temperatura desejada. O banho termostatizado foi conectado na entrada da primeira célula e na saída da segunda. A ligação entre as duas células foi feita por meio do uso de uma mangueira de látex. A verificação da temperatura foi feita através do uso de dois termopares FullGauge (TIC-17RGTi) que foram acoplados em cada uma das células e mediam a temperatura na região central. Para cada uma das células utilizou-se um agitador eletromagnético (Ika, RH D-KT/C) e uma barra magnética $(1,512 \mathrm{~cm}$ de comprimento e 0,607 $\mathrm{cm}$ de diâmetro) revestida com teflon que promoveram a agitação da mistura por um período de $2 \mathrm{~h}$ seguido de $2 \mathrm{~h}$ de repouso. Estes períodos foram definidos por Silva et al (2015).

Figura 1 - Unidade experimental.

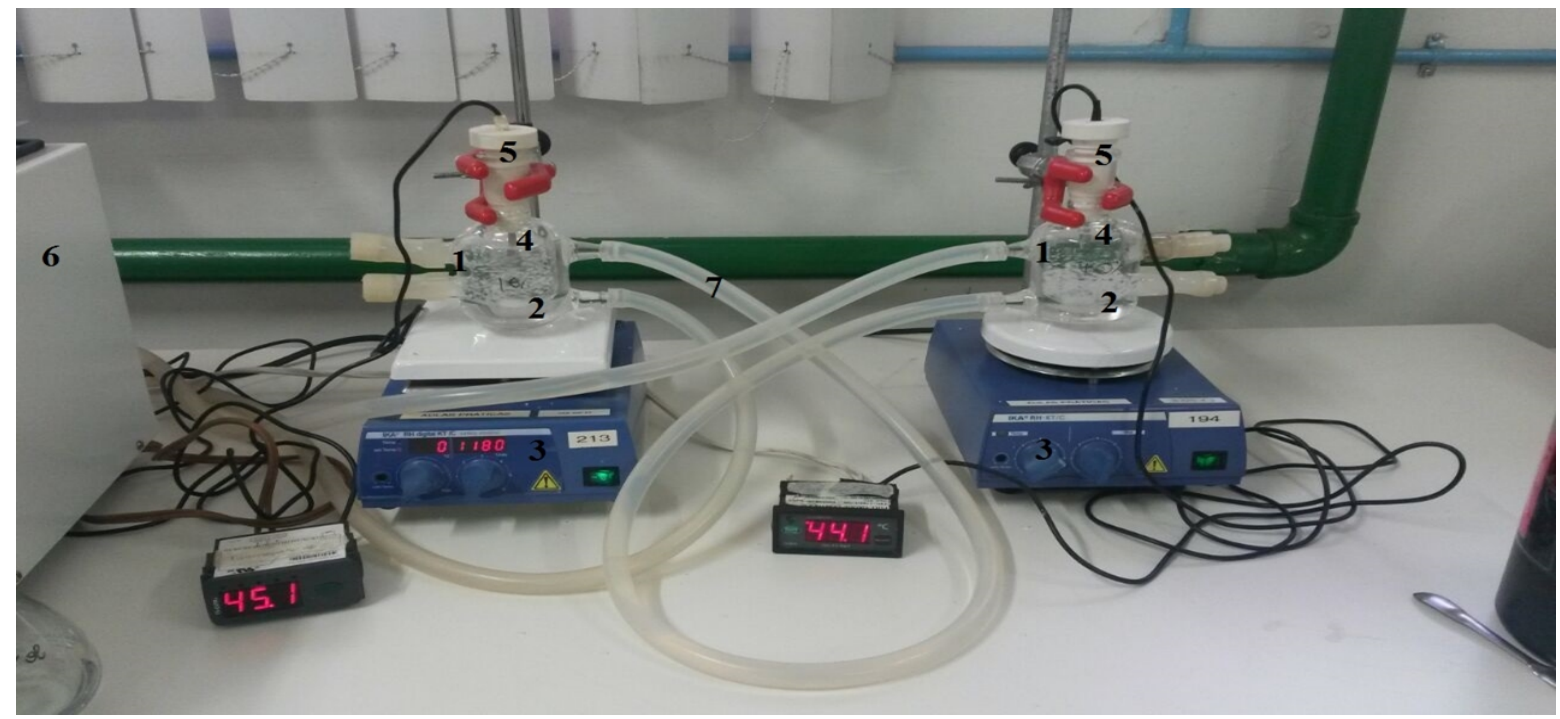


Pela Figura 1, pode-se observar que (1) são as células de equilíbrio, (2) as barras magnéticas, (3) os agitadores eletromagnéticos, (4) os termopares, (5) as rolhas que vedam a célula, (6) o banho termostatizado e (7) a mangueira de látex que conecta as células.

\subsection{Procedimento Experimental}

Foram realizados experimentos em uma faixa de temperatura de 278,15 a $333,15 \mathrm{~K}$ para soluções de isopropanol+água contendo 10 e $40 \%$ em massa de isopropanol. A massa dos solventes era medida em béqueres separados com o uso de uma balança analítica (Shimadzu, AUW320) com precisão de 0,0001g, considerando-se a pureza de cada um e depois eram transferidos para um balão volumétrico de $250 \mathrm{~mL}$ onde era feita a homogeneização da mistura através de agitação manual. Em cada uma das células colocavam-se as respectivas soluções de isopropanol+água na proporção em que se desejava analisar e ureia em excesso para garantir obtenção de uma solução saturada. O período de agitação das soluções foi de duas horas seguido de duas horas de repouso.

Após terminado o tempo de repouso foram retiradas quatro amostras de 4 a $5 \mathrm{~mL}$ de cada solução com o auxílio de uma seringa de vidro com capacidade de $10 \mathrm{~mL}$. Durante o experimento a seringa foi mantida submersa em uma água com a mesma temperatura do banho para evitar a cristalização da ureia dentro da seringa o que levaria a erros. Para cada amostra um béquer de $25 \mathrm{~mL}$ foi lavado, seco, pesado e numerado. Cada amostra foi retirada da célula e logo em seguida colocada no respectivo béquer para que sua pesagem fosse efetuada. Logo depois da pesagem do béquer com a amostra foi feita a etapa de secagem em que os béqueres foram colocados na estufa (Marconi, MA-033) a 338,15 K .

As amostras foram deixadas na estufa (Marconi, MA-033) por um período de $24 \mathrm{~h}$ na temperatura de $338,15 \mathrm{~K}$. Após esse período as amostras foram colocadas em um dessecador com sílica por 30 min e então foi feita a pesagem do béquer contendo ureia cristalizada para determinar a massa de ureia seca. As amostras foram pesadas por cerca de 4 dias até massa constante assim como foi feito por Silva et al. (2015). Com a massa do béquer vazio, a massa do béquer com a solução e a massa do béquer com a ureia seca foi possível determinar a solubilidade para cada concentração de isopropanol e para cada temperatura. O resultado de solubilidade obtido foi a média aritmética dos valores de solubilidade encontrados para cada amostra.

\section{RESULTADOS E DISCUSSÃO}

Com o uso dos dados coletados: massa dos béqueres, massa da amostra com o solvente e massa da amostra seca, juntamente com a Equação 1, foi possível calcular a solubilidade da ureia para todas as temperaturas e percentagens gravimétricas de isopropanol estudadas.

$$
S=\frac{m_{u}}{m_{s}} \times 100
$$

sendo: $S$ a solubilidade em (g/100 g), $m_{u}$ a massa da ureia $(\mathrm{g})$ e $m_{s}$ a massa do solvente $(\mathrm{g})$. 
As Tabelas 1 e 2 apresentam os resultados de solubilidade para as concentrações de 10 e $40 \%(\mathrm{~m} / \mathrm{m})$ de isopropanol, respectivamente.

Tabela 1 - Solubilidade da ureia em isopropanol+água (10\% isopropanol m/m).

\begin{tabular}{cc}
\hline$T \pm \delta(\mathrm{K})$ & $S \pm \delta$ (g ureia/100g solvente) \\
\hline $278,5 \pm 0,2$ & $66,1569 \pm 0,0186$ \\
$283,3 \pm 0,1$ & $79,1430 \pm 0,2430$ \\
$288,3 \pm 0,0$ & $88,4284 \pm 0,1930$ \\
$293,2 \pm 0,2$ & $98,1323 \pm 1,5126$ \\
$298,1 \pm 0,2$ & $103,6148 \pm 1,7900$ \\
$303,4 \pm 0,2$ & $125,9579 \pm 0,2386$ \\
$307,9 \pm 0,1$ & $140,0652 \pm 0,7371$ \\
$312,8 \pm 0,4$ & $153,1213 \pm 1,2367$ \\
$318,4 \pm 0,3$ & $161,1721 \pm 4,4737$ \\
$322,5 \pm 0,5$ & $185,1029 \pm 0,8107$ \\
$327,9 \pm 0,2$ & $192,8883 \pm 5,1605$ \\
$332,6 \pm 0,5$ & $226,7360 \pm 0,2805$ \\
\hline
\end{tabular}

Tabela 2 - Solubilidade da ureia em isopropanol+água (40\% isopropanol m/m).

\begin{tabular}{cc}
\hline$T \pm \delta(\mathrm{K})$ & $S \pm \delta(\mathrm{g}$ ureia/100g solvente $)$ \\
\hline $278,2 \pm 0,1$ & $37,8215 \pm 0,2496$ \\
$283,2 \pm 0,0$ & $54,3019 \pm 0,0810$ \\
$293,1 \pm 0,1$ & $68,4791 \pm 0,2206$ \\
$298,2 \pm 0,2$ & $79,2912 \pm 0,1237$ \\
$303,4 \pm 0,2$ & $88,3213 \pm 0,2837$ \\
$307,7 \pm 0,1$ & $98,1705 \pm 0,8727$ \\
$313,1 \pm 0,4$ & $106,2550 \pm 4,8082$ \\
$318,4 \pm 0,3$ & $127,1020 \pm 0,2741$ \\
$322,7 \pm 0,2$ & $138,0328 \pm 0,7339$ \\
$328,0 \pm 0,2$ & $149,8612 \pm 4,2601$ \\
$333,0 \pm 0,1$ & $174,2320 \pm 3,8795$ \\
\hline
\end{tabular}

Analisando-se as Tabelas 1 e 2 é possível observar que os resultados de solubilidade para ambos os sistemas químicos estudados apresentaram desvios baixos, desvio médio de $0,95 \%$ para a solução de $10 \%(\mathrm{~m} / \mathrm{m})$ e de $1,17 \%$ para a solução de $40 \%(\mathrm{~m} / \mathrm{m})$ de isopropanol. 
A solução de $10 \%$ de isopropanol $(\mathrm{m} / \mathrm{m})$ também apresentou uma solubilidade maior, o que indica que a solubilidade da ureia é maior em água do que em isopropanol. Nota-se que houve um aumento na solubilidade da ureia com o aumento da temperatura. O motivo de tal comportamento se deve ao fato de que a dissolução da ureia é um processo endotérmico, o qual necessita de uma absorção de energia para ocorrer, portanto, o aumento da temperatura favorece esse processo.

\section{CONCLUSÃO}

Com os resultados experimentais de solubilidade constatou-se que houve um decréscimo no valor de solubilidade da ureia com o aumento da percentagem de isopropanol, o que demonstra que a ureia é mais solúvel em água do que em isopropanol. Isso se deve ao fato de que a água apresenta uma constante dielétrica maior que a do isopropanol e a solubilidade da ureia é diretamente proporcional a constante dielétrica dos solventes.

Verificando-se a influência da temperatura na solubilidade da ureia foi possível concluir que a solubilidade da ureia aumentou significativamente com o aumento da temperatura para ambas as soluções estudadas. Esse comportamento era esperado devido ao fato de que a dissolução da ureia é um processo endotérmico.

Como os desvios padrão encontrados foram baixos, pode-se constatar que o método gravimétrico e a unidade experimental foram eficientes para a determinação dos resultados de solubilidade da ureia. Os dados obtidos neste trabalho podem ser muito úteis para a técnica de quimigação que consiste em distribuir uma solução de um fertilizante ou herbicida através do sistema de irrigação. Essa técnica precisa de dados sobre o comportamento da solubilidade do composto para ser bem empregada e os dados obtidos neste trabalho podem ajudar na otimização desta técnica, assim como no desenvolvimento de novos equipamentos.

\section{AGRADECIMENTOS}

Agradecemos a Fundação de Amparo à Pesquisa do Estado de Minas Gerais (FAPEMIG) pela bolsa de Iniciação Científica e também à Faculdade de Engenharia Química da Universidade Federal de Uberlândia pelo incentivo a pesquisa e estrutura física oferecida para o desenvolvimento desta pesquisa no Laboratório de Cristalização.

\section{REFERÊNCIAS}

KURALAY, F.; ÖZYÖRÜK, H.; YILDIZ, A. Potentiometric enzyme electrode for urea determination using immobilized urease in poly( vinylferrocenium ) film. Sens. Actuators B, v. 109, p. 194-199, 2005.

LEE, F. M.; LAHTI, L. E. Solubility of urea in water-alcohol mixtures. J. Chem. and Eng. Data, v. 17, p. 304-306, 1972.

SAPOUNDJIEV, D.; LORENZ, H.; SEIDEL-MORGENSTERN, A. Determination of solubility data by means of calorimetry. Thermochim. Acta, v. 436, p. 1-9, 2005. 
SILVA, A. P. Determinação da solubilidade do fertilizante ureia em solventes puros e em misturas hidro alcoólicas. 2015. 118 p. Dissertação de Mestrado, Faculdade de Engenharia Química, Universidade Federal de Uberlândia, Uberlândia, 2015.

SOPER, A.K.; CASTNERB, E. W.; LUZAR A. Impact of urea on water structure: a clue to its properties as a denaturant? Biophys. Chem., v. 105, p. 649- 666, 2003.

STORM, T. D.; HAZLETON, R. A.; LAHTI, L. E. Some effects of solvent properties on nucleation. J. Cryst. Growth, v.7, p. $55-60,1970$.

YIN, S.; AITA, Y.; KOMATSU, M.; SATO, T. Some effects of solvent properties on nucleation. J. Eur. Ceram. Soc., v.26, p. 2735 -2742, 2006. 